\title{
Abnormal regulation of the oestrogen receptor in benign breast lesions
}

\author{
B S Shoker, C Jarvis, R B Clarke, E Anderson, C Munro, M P A Davies, D R Sibson, \\ J P Sloane
}

Department of Pathology, University of Liverpool, The Duncan Building, Daulby Street, Liverpool L69 3GA, UK

B S Shoker

C Jarvis

C Munro

J P Sloane

Clinical Research Department, Christie Hospital NHS Trust, Manchester M20 4BX, UK

R B Clarke

E Anderson

JK Douglas Cancer Research Laboratory, Clatterbridge Hospital, Bebington, Wirral CH63 4JY, UK M P A Davies

D R Sibson

Correspondence to: Dr Shoker

b.s.shoker@ Liverpool.ac.uk

Accepted for publication 12 April 2000

\begin{abstract}
Background-In normal breast tissue the oestrogen receptor (ER) and the proliferation associated antigen Ki67 are negatively associated, indicating that ER+ cells are non-dividing, or that the receptor is downregulated as cells enter cycle. This relation is completely or partially lost in many ER+ breast cancers and in in situ proliferations associated with an increased cancer risk, where coexpression of the two markers is often found.
\end{abstract}

Aims-To determine whether similar changes can be identified in other risk associated breast lesions.

Patients/Methods-Paraffin wax blocks from 12 cases of lactational change, 21 apocrine metaplasias, 22 duct ectasias, 20 sclerosing adenosis, 20 fibroadenomas, 19 phyllodes tumours, 20 radial scars, 21 papillomas (15 solitary and six multiple), 15 gynaecomastias, and nine postmortem male breast tissues were retrieved. Immunohistochemistry was used to determine the expression of ER and dual labelling immunofluorescence was used to detect cells expressing both ER and Ki67.

Results-Increased numbers of ER+ cells were seen in sclerosing adenosis, radial scars, papillomas, fibroadenomas, and phyllodes tumours but not in apocrine cysts (where no ER+ cells were detected) or duct ectasia (where normal numbers were found). As in the normal breast, the proportion of ER+ cells increased with age in all lesions with the exception of fibroadenomas. Coexpression of ER and $\mathrm{Ki} 67$ was found in an increased proportion of cells of all risk associated lesions studied. ER+ cells were less likely to be dividing than ER- cells in all cases, although this was significant only for sclerosing adenosis. The data on sclerosing adenosis, radial scars, papillomas, and fibroadenomas are comparable with those reported previously in hyperplasia of usual type, whereas those in duct ectasia are similar to those of the normal breast. The findings in all lesions, however, differed from those in ductal carcinoma in situ, where proportions of $\mathrm{ER}+$ and $\mathrm{ER}+/ \mathrm{Ki} 67+$ cells are higher and the relation between ER+ cell numbers and age is lost. Thus, the nature and degree of dysregulation of ER in benign breast lesions is broadly in accordance with the degree of risk of developing breast cancer with which they are associated. In gynaecomastia, the proportions of
ER+ and ER+/Ki67+ cells were comparable with those seen in benign female breast lesions, but changes with age were not observed. However, the changes in gynaecomastia were similar to those seen in normal male breast.

Conclusion-These findings are in keeping with the contention that the dissociation of ER and Ki67 expression is a very early change in the pathway to many breast cancers. However, this change might only have preneoplastic importance in the hormonal milieu of the female breast.

(f Clin Pathol 2000;53:778-783)

Keywords: oestrogen receptor; proliferation; benign breast; precancerous breast

Oestrogen is thought to be important in the pathogenesis of breast cancer, probably through the stimulation of epithelial proliferation via the oestrogen receptor (ER). ${ }^{1}$ It is associated with most of the epidemiological risk factors such as the ages at menarche, first child, and menopause, and the use of oral contraception or hormone replacement therapy. ${ }^{2}$ In the normal breast, ER+ cells are in the minority, but the proportion increases somewhat with age. There is a negative association between the expression of ER and the proliferation marker Ki67, indicating that either ER+ cells are non-dividing or that the receptor is downregulated as cells enter cycle. This important relation breaks down in many ER+ cancers, where the receptor is often detected on proliferating cells. ${ }^{3}$ We have recently studied ER expression in the in situ proliferations hyperplasia of usual type (HUT), atypical ductal hyperplasia $(\mathrm{ADH})$, ductal carcinoma in situ (DCIS), and lobular in situ neoplasia (LIN) because there is strong evidence that they are precursors of breast cancer, ${ }^{4-7}$ and because they form a histological spectrum in which the molecular changes in the development of cancer can be studied. We showed that the proportion of ER+ cells is increased above normal postmenopausal values in all of these proliferations and that in all except HUT the normal increase with age is lost. ${ }^{8}$ Furthermore, the proportion of $\mathrm{ER}+/ \mathrm{Ki} 67+$ cells was increased in all lesions and the negative association between ER and Ki67 was lost in all except HUT. ${ }^{9}$ Thus, increases in $\mathrm{ER}+/ \mathrm{Ki} 67+$ cells and the breakdown of normal age regulatory mechanisms of ER+ cell numbers might represent early precancerous changes.

However, little is known about these relations in other benign breast lesions, some of 
which have also been shown to be associated with an increased risk of developing breast cancer. Several studies have shown that there is an increased relative risk of developing breast cancer associated with sclerosing adenosis, ${ }^{10}$ intraduct papilloma, ${ }^{71}$ radial scar, ${ }^{12-14}$ and even fibroadenoma. ${ }^{615} 16$ Other changes such as apocrine cysts, duct ectasia, and gynaecomastia are not thought to be associated with an increased risk of cancer. The purpose of our study was to determine whether any of these lesions contained excessive numbers of ER+ cells or showed a breakdown in the normal relations between ER expression, age, and cell proliferation and, if so, whether the presence and degree of the abnormalities related to cancer risk.

\section{Materials and methods \\ PATIENTS}

Paraffin wax blocks and slides of 165 cases spanning a 10 year period were retrieved from the files of the department of pathology at the Royal Liverpool University. They comprised 12 showing lactational change, 21 apocrine metaplasias, 22 duct ectasias, 20 sclerosing adenosis, 20 fibroadenomas, 19 phyllodes tumours, 20 radial scars, 21 papillomas (15 solitary and six multiple), 15 gynaecomastias, and nine postmortem male breast tissues. Two pathologists (BSS, JPS) made all the diagnoses following the pathology guidelines of the NHS breast screening programme. ${ }^{17}$ Some of the blocks studied contained more than one lesion. Immunohistochemistry and dual labelling immunofluorescence were performed.

\section{IMMUNOHISTOCHEMISTRY}

All the tissue samples were fixed in $10 \%$ formalin followed by four hours fixation in methacarn and then routinely processed to paraffin wax. The ER was detected with a mouse monoclonal anti-ER antibody (clone 1D5; Dako Ltd, Ely, Cambridge, UK). Immunohistochemistry was performed using a standard streptavidin-biotin method with previous microwave antigen retrieval. Negative controls, in which the primary antibody was omitted, and three positive controls of ER+ breast carcinoma of varying staining intensities were included in each batch of immunohistochemistry. The method was identical to that used for the routine assessment of ER status in which our laboratory performs well in the UK external quality assessment scheme. To maximise the consistency of scoring, only nuclei showing moderate or strong staining were regarded as positive. The percentage of ER+ cells for each lesion was calculated.

DUAL LABELLING IMMUNOFLUORESCENCE

The method used was similar to that described previously. ${ }^{3}$ Briefly, proliferation and ER receptor expression were visualised using antibodies raised against the Ki67 antigen, which is expressed in the late $\mathrm{G} 1, \mathrm{~S}, \mathrm{G} 2$, and $M$ phases of the cell cycle (Ki67p; Novocastra, Newcastle upon Tyne, UK), and against the human ER (clone 1D5). Dual fluorescent label immunohistochemistry was carried out after microwave antigen retrieval, and primary antibody binding was detected with a fluorescein labelled (green) secondary antibody in the case of Ki67 and a Cy3 labelled (red) antibody for ER. Cell nuclei were then counterstained with 4',6diamidino-2-phenylindole, which fluoresces blue. Control slides were included in each analysis by performing the same procedures and substituting non-immune serum for primary antibodies and secondary antibodies individually.

Quantification of the fluorochromes was performed by either scoring the entire lesion or between 1000 and 4000 cells across several representative fields (chosen using a 4',6diamidino-2-phenylindole filter), depending on the size of the lesion. Each field was examined under a high powered lens for the red (Cy3), green (fluorescein), and blue (4',6diamidino-2-phenylindole) fluorochromes using the appropriate filters in succession to assess the presence or absence of double labelled cells. A triple band filter in which all three fluorochromes could be seen simultaneously was used for confirmation of dual staining. In addition, because many high powered fields contained few if any proliferating cells, the entire number or a minimum of 100 $\mathrm{Ki} 67+$ cells within a lesion were assessed for coexpression of ER to give a better overall indication of dual positivity within a lesion.

\section{EVALUATION OF DATA}

The data were analysed by the Pearson product moment correlation coefficient and the nonparametric Mann Whitney and Kruskal Wallis tests using SPSS software for Windows (release $6.1)$.

\section{Results}

ER EXPRESSION AND ITS RELATION TO PATIENT AGE

All the female breast lesions studied, except cysts showing apocrine metaplasia, contained ER+ epithelial cells. In most of these lesions the percentage of ER+ cells correlated positively with the patient's age; however, the results were significant only for papillomas and phyllodes tumours, with fibroadenomas showing no age correlation (table 1). Lactating breast and the breast lesions associated with no increased risk of developing carcinoma-duct ectasia and apocrine metaplasia-contained few or no ER+ cells, even when they occurred in postmenopausal women. In comparison with the breast lesions associated with no increased risk, the breast lesions associated with a low risk of developing cancer (fibroadenoma, sclerosing adenosis, papillomas, and radial scars) contained increased numbers of ER+ cells, and this was significant (Mann Whitney, highest $p=0.001$ for fibroadenomas). The low risk breast lesions also contained a higher mean percentage of ER+ cells than age matched (most cases age matched to within 2 years) normal breast tissue (Mann Whitney, highest $\mathrm{p}=0.04$ for sclerosing adenosis). However, there was pronounced heterogeneity in ER staining within similar lesions. The range of ER+ cells in all the lesions 
Table 1 Relation between proportion of the oestrogen receptor (ER) positive cells and age in breast lesions associated with no or a low increased risk of subsequently developing breast cancer

\begin{tabular}{|c|c|c|c|c|c|c|c|c|c|c|c|}
\hline \multirow[b]{3}{*}{ Breast lesions } & \multicolumn{9}{|l|}{ Age } & \multirow{2}{*}{\multicolumn{2}{|c|}{$\begin{array}{l}\text { Age correlated with } E R \\
\text { expression }\end{array}$}} \\
\hline & \multicolumn{3}{|l|}{$<<46$} & \multicolumn{3}{|l|}{$46-55$} & \multicolumn{3}{|l|}{$>55$} & & \\
\hline & No. cases & $\begin{array}{l}\text { Mean \% } \\
\text { of ER+ } \\
\text { cells }\end{array}$ & $S D$ & No. cases & $\begin{array}{l}\text { Mean \% } \\
\text { of ER+ } \\
\text { cells }\end{array}$ & $S D$ & No. cases & $\begin{array}{l}\text { Mean \% } \\
\text { of ER+ } \\
\text { cells }\end{array}$ & $S D$ & $\begin{array}{l}\text { Pearsons } \\
\text { correlation } \\
\text { coefficient }\end{array}$ & $p$ Value \\
\hline ^Normal female & 12 & 11 & 7 & 31 & 27 & 20 & 53 & 34 & 22 & 0.2803 & 0.006 \\
\hline$\star \star$ Lactating breast & 12 & 3 & 5 & - & - & - & - & - & - & - & - \\
\hline Duct ectasia & 4 & 5 & 0 & 7 & 7 & 5 & 11 & 15 & 9 & 0.4103 & 0.058 \\
\hline Sclerosing adenosis & 4 & 52 & 12 & 8 & 38 & 25 & 8 & 72 & 16 & 0.4003 & 0.080 \\
\hline Radial Scar & 2 & 15 & 0 & 11 & 45 & 24 & 7 & 47 & 21 & 0.3644 & 0.114 \\
\hline Papilloma (all) & 6 & 17 & 15 & 5 & 31 & 18 & 10 & 60 & 25 & 0.5692 & 0.007 \\
\hline Papilloma (solitary) & 4 & 12 & 10 & 4 & 35 & 18 & 7 & 57 & 28 & 0.5642 & 0.028 \\
\hline Papilloma (multiple) & 2 & 27 & 25 & 1 & 15 & - & 3 & 67 & 18 & 0.6435 & 0.168 \\
\hline Fibroadenoma & 12 & 37 & 12 & 3 & 15 & 9 & 5 & 27 & 27 & -0.1064 & 0.655 \\
\hline Phyllodes tumour & 8 & 40 & 26 & 1 & 50 & - & 10 & 73 & 19 & 0.5438 & 0.016 \\
\hline Male (all) & 10 & 61 & 22 & 3 & 78 & 13 & 11 & 56 & 24 & -0.0405 & 0.851 \\
\hline Normal male & 0 & - & - & 2 & 85 & 7 & 7 & 55 & 27 & -0.1852 & 0.633 \\
\hline Gynaecomastia & 10 & 61 & 22 & 1 & 65 & - & 4 & 57 & 23 & -0.0457 & 0.871 \\
\hline
\end{tabular}

${ }_{\star}^{\star}$ Data from Shoker et al. ${ }^{8}$

${ }^{\star \star}$ Although lactating breast contained only a few moderate or strongly staining cells many of the cells (mean, $18 \%$ ) showed weak or faint staining. Correlation of ER with age was not calculated because of the narrow age range of the patients.

was wide (mean range, $68 \%$ ) and for fibroadenomas it was between $1 \%$ and $85 \%$, whereas for papillomas the range was $1-95 \%$.

ER AND Ki67 DUAL EXPRESSION

Ki67+ cells were also present within all the lesions studied, ranging from $1.5 \%$ of cells in sclerosing adenosis to $4.4 \%$ in fibroadenomas (table 2). There was less variability in the expression of Ki67 than ER within similar and between different lesions, although for fibroadenomas it did vary between $1.6 \%$ and $12 \%$. However, only papillomas had a significantly higher mean percentage of Ki67+ cells than age matched normal breast tissue (Mann Whitney, $p=0.001$ ). The proportion of dual positive cells is given as the percentage of all cells counted (table 2, column 7) and as the percentage of $\mathrm{Ki} 67+$ that were also ER+ (table 2 , column 10). The former gives an indication of the overall proportion of dual labelled cells but is dependent on the total numbers of ER+ and Ki67+ cells. The latter is not dependent on overall cell numbers and consequently is more likely to reveal an abnormal relation between the two markers. Cells dually expressing ER and Ki67 were not seen in apocrine metaplasia (fig 1A) or duct ectasia (fig 1B). In contrast, the lesions associated with a low cancer risk contained significantly greater numbers of dual expressing cells (fig 1C), and in all except scle- rosing adenosis the percentage of $\mathrm{ER}+\mathrm{Ki} 67+$ cells was significantly increased compared with normal premenopausal and postmenopausal lobules (table 2), and in comparison with age matched normal breast tissue (Mann Whitney, highest $\mathrm{p}=0.05$ for radial scars).

\section{OBSERVED/EXPECTED RATIOS}

Because the lesions have different numbers of ER+ and Ki67+ cells, the percentages of double labelled cells that would be expected if the two variables were independent have been calculated. This was calculated for each lesion by multiplying the percentage of ER+ and Ki67+ cells and then dividing by 100 . The observed values were lower than the expected values for all the lesions, although this was significant only in sclerosing adenosis $(\mathrm{p}=0.0028)$ (table 2). Calculations for duct ectasia and apocrine metaplasia were not possible because of the absence of dual labelled cells.

The observed/expected $(\mathrm{O} / \mathrm{E})$ ratio gives an indication of whether the two markers are positively or negatively associated with each other and the strength of the association. In the former, values of $>1$ would be expected and in the latter, $<1$. Figure 2 is a box plot of the $\mathrm{O} / \mathrm{E}$ values. The lesions associated with no increased risk of breast carcinoma have median values of 0 , whereas all the low risk lesions have intermediate values between 0 and 1 . All cases

Table 2 Coexpression of the oestrogen receptor (ER) and a proliferation marker (Ki67) in breast lesions associated with no or a low increased risk of subsequently developing breast cancer

\begin{tabular}{|c|c|c|c|c|c|c|c|c|c|c|}
\hline Lesions & $\begin{array}{l}\text { Mean age } \\
(S D)\end{array}$ & $\begin{array}{l}\text { No. of } \\
\text { cases }\end{array}$ & $\begin{array}{l}\text { Mean no. cells } \\
\text { counted (SD) }\end{array}$ & $\begin{array}{l}\text { Mean } \\
\text { positiv } \\
\text { (SD) }\end{array}$ & $\begin{array}{l}\% \text { ER } \\
\text { ve cells }\end{array}$ & $\begin{array}{l}\text { Mean \% Ki67 } \\
\text { positive cells } \\
\text { (SD) }\end{array}$ & $\begin{array}{l}\text { Mean \% dual } \\
\text { positive cells } \\
\text { (SD) }\end{array}$ & $\begin{array}{l}\text { Mean \% dual } \\
\text { positive cells } \\
\text { expected (SD) }\end{array}$ & $\begin{array}{l}\text { Mean } \\
\text { observed } \\
\text { lexpected ratio } \\
(S D)\end{array}$ & $\begin{array}{l}\text { Mean \% of } \\
\text { total Ki67 that } \\
\text { are ER+ (SD) }\end{array}$ \\
\hline${ }^{\star}$ Normal (premenopausal) & $42(10)$ & 14 & $1475(885)$ & 6.8 & $(5.4)$ & $2.6(3.1)$ & $0.01(0.02)$ & $0.17(0.37)$ & $0.05(0.14)$ & $0.44(1.44)$ \\
\hline${ }^{\star}$ Normal (postmenopausal) & $65(7.5)$ & 14 & $1099(328)$ & 42 & (23) & $0.34(0.33)$ & $0.04(0.05)$ & $0.11(0.12)$ & $0.39(0.52)$ & (20) \\
\hline Lactation & $29(5.8)$ & 10 & $1623(353)$ & 1.33 & $(1.15)$ & $2.5(2.6)$ & $0.01(0.03)$ & $0.03(0.03)$ & $0.02(0.52)$ & $1.03(1.79)$ \\
\hline Apocrine metaplasia & $57(8.9)$ & 13 & $954(829)$ & 0.0 & $(0.0)$ & $1.10(1.06)$ & $0.0(0.0)$ & $0.0(0.0)$ & - & $0.0(0.0)$ \\
\hline Duct ectasia & $51(15)$ & 10 & $915(261)$ & 6.5 & $(9.0)$ & $1.57(1.32)$ & $0.0 \quad(0.0)$ & $0.12(0.27)$ & $0.0 \quad(0.0)$ & $0.0(0.0)$ \\
\hline Sclerosing adenosis & $54(12)$ & 13 & $1353(858)$ & 49 & $(24)$ & $1.01(1.55)$ & $0.18(0.52)$ & $0.37(0.56)$ & $0.22(0.31)$ & $12 \quad(21)$ \\
\hline Radial scar & $56(6.6)$ & 13 & 2417 (946) & 44 & (18) & $1.57(1.16)$ & $0.28(0.34)$ & $0.63(0.50)$ & $0.32(0.27)$ & (15) \\
\hline Papilloma & $53(12)$ & 11 & $1795(437)$ & 50 & (18) & $3.1(2.5)$ & $0.79(0.83)$ & $1.60(1.57)$ & $0.54(0.32)$ & (16) \\
\hline Fibroadenoma & $37(11)$ & 10 & $1375(202)$ & 45 & (23) & $4.4 \quad(3.7)$ & $1.03(1.25)$ & $1.92(1.71)$ & $0.46(0.33)$ & (22) \\
\hline Phyllodes tumour & $53(14)$ & 10 & $1245(157)$ & 68 & (16) & $4.1 \quad(4.0)$ & $1.50(1.54)$ & $2.50(2.16)$ & $0.44(0.27)$ & (18) \\
\hline Normal male & $65(9)$ & 8 & $654(374)$ & 43 & (29) & $0.39(0.51)$ & $0.11(0.18)$ & $0.18(0.24)$ & $0.57(0.56)$ & (41) \\
\hline Gynaecomastia & $33(16)$ & 11 & $1510(272)$ & 63 & (23) & $1.7(1.5)$ & $0.56(0.74)$ & $0.96(0.87)$ & $0.47(0.32)$ & (24) \\
\hline
\end{tabular}

${ }^{\star}$ Data from Shoker et al. ${ }^{9}$ 

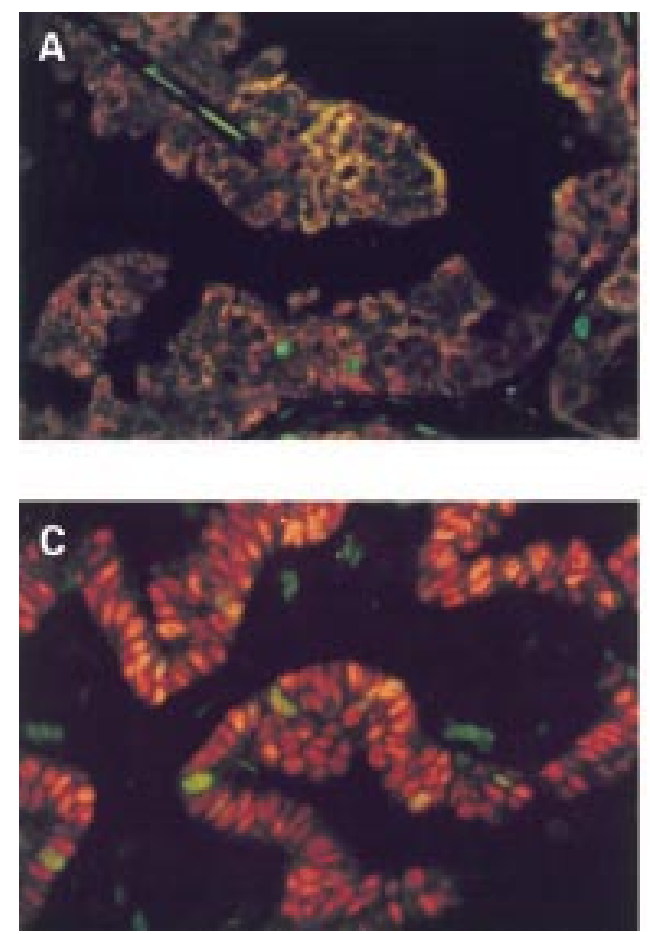

Figure 1 The distribution of oestrogen receptor (ER) and Ki67 antigen in benign breast lesions visualised by indirect immunofluorescence using fluorochromes Cy3 (orange/red) for ER and fluorescein (green) for Ki67 antigen. (A) An apocrine cyst containing occasional Ki67+ cells but no ER + cells. (B) Duct ectasia showing mutual exclusion between ER and Ki67. (C) A solitary papilloma showing extensive ER positivity and containing occasional dual labelled cells. (D) Gynaecomastia showing pronounced ER positivity and containing occasional dual labelled cells.

in which the observed and expected values were 0 (for example, all cases of apocrine metaplasia) were excluded from the ratio analyses.

MALE BREAST TISSUE

The percentage of ER+ cells in normal postmortem male breast tissue and gynaecomastia specimens was similar, although gynaecomastia specimens did have a significantly

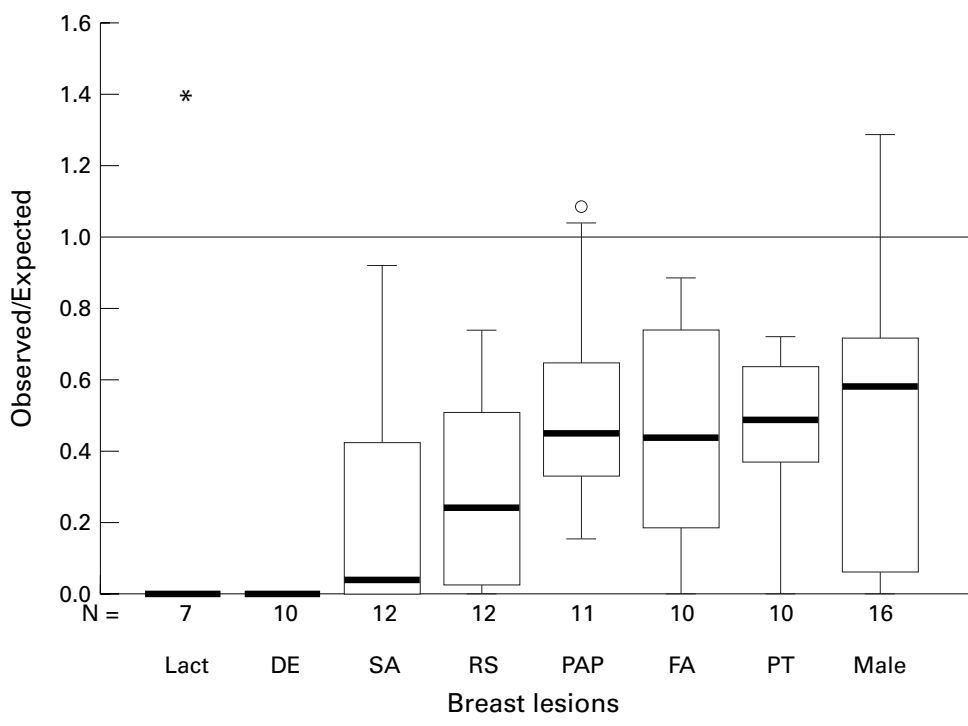

Figure 2 Observed/expected values plotted for oestrogen receptor $(E R)+/ K i 67+$ cells in breast lesions associated with no or a low increased risk of subsequently developing breast cancer. Box plot graph in which the line across the box indicates the median, the box contains the values between the 25th and 75th centiles, and the whiskers extend to the highest and lowest values, excluding the outliers. The small open circle and the asterisk identify the outliers and extreme values, respectively. DE, duct ectasia; FA, fibroadenoma; Lact, lactating breast; Male, normal male and gynaecomastia; PAP, papilloma; PT, phyllodes tumour; $R S$, radial scar; $S A$, sclerosing adenosis.
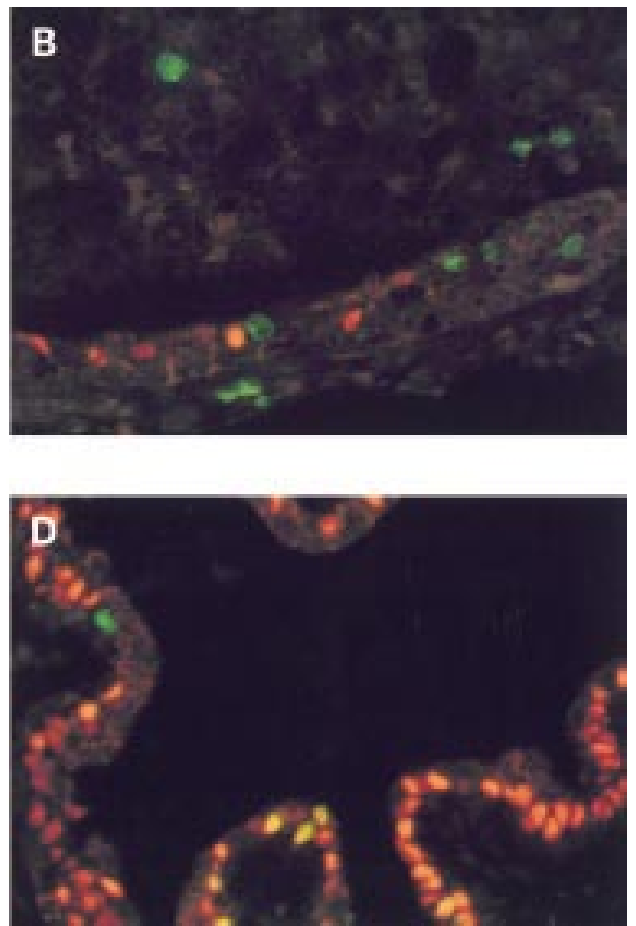

greater percentage of Ki67+ cells $(p=0.02)$ and a greater percentage of dual expressing cells $(\mathrm{p}=0.06)$ (fig $1 \mathrm{D}) . \mathrm{O} / \mathrm{E}$ ratios, however, were similar for both. Male breast tissue (normal and gynaecomastia) has similarities to the low risk lesions in the female-a relatively high percentage of ER+ and dual expressing cells with an intermediate median value for the $\mathrm{O} / \mathrm{E}$ ratio (table 2).

\section{Discussion}

There is overwhelming evidence that the effects of oestrogen are important in the development of human breast cancer. We have shown previously that the percentage of ER+ cells is increased within in situ proliferations (HUT, $\mathrm{ADH}, \mathrm{DCIS}$, and LIN) of the breast and that the proportion of these cells in different lesions correlates with the risk attributed to them in prospective studies. ${ }^{8}$ Furthermore, a fundamental change appears to occur between the HUT and ADH stages. The proportion of ER+ cells in the former, as in the normal breast, increases with age, whereas in the latter, in common with ER+ DCIS, no age association is seen, the percentage of ER+ cells being high at all ages. ${ }^{8}$ This suggests that the regulation of the expression of ER or the control of ER+ cells numbers escapes the normal age related regulatory mechanisms at the $\mathrm{ADH}$ stage.

In our present study we have undertaken similar investigations of other breast lesions, some of which have been shown to be associated with an increased relative risk of developing breast cancer comparable with that associated with HUT. ${ }^{5}{ }^{10-16}$ These low risk lesions had increased proportions of ER+ cells, whereas those not associated with increased 
risk did not. An age related increase in the proportion of ER+ cells was seen in most lesions, but it was less pronounced than that seen in normal breast tissue or in HUT. ${ }^{8}$ However, the age related variation was significant in papillomas and phyllodes tumours only, and was not demonstrable in fibroadenomas. All the benign breast lesions showed a pronounced variation for the markers assessed. This heterogeneity might be related to the relative lack of consensus in the literature that they are associated with an increased risk in comparison with HUT, where the consensus is strong. Perhaps only subsets of the lesions studied are really associated with an increased cancer risk

It is likely that the increase in ER+ cells with age is associated with declining plasma oestrogen concentrations. Furthermore, it is conceivable that the major architectural disturbances associated with the lesions studied in our investigation and the pronounced differences in their stromal components could modify local oestrogen concentrations and consequently the number of ER+ cells. Indeed, differences in the expression of other receptors within fibroadenomas have already been described. ${ }^{18}$ The difference between fibroadenomas and phyllodes tumours in our study is perplexing, but stromal differences might be important. It is also worth noting that phyllodes tumours have not been found to be associated with an increased risk of developing breast cancer although, to the authors' knowledge, they have not been studied extensively in this context. The fact that certain subsets of fibroadenomas might be associated with increased risk has been established relatively recently. ${ }^{15}$

In normal premenopausal lobules there is a negative association between steroid receptor expression and cell proliferation, as judged by the lack of dual immunostaining for ER and the proliferation marker Ki67. ${ }^{3}$ However, this normal relation is lost in many invasive ER+ breast cancers, ${ }^{3}$ in which a variable proportion of $\mathrm{ER}+$ cells is also Ki67+. A similar phenomenon is seen within in situ carcinomas and atypical hyperplasias, but in HUT the negative association is at least partly retained. ${ }^{9}$ Although the negative association between ER and Ki67 was lost in all these lesions, coexpression was not seen with greater frequency than would be expected by chance if the two markers were expressed independently of each other. Put another way, ER+ cells were no more likely to be dividing than ER negative cells. These lesions are thus characterised by a lack of suppression of ER expression as cells enter cycle, or of ER positive cells entering the cycle, rather than a predisposition for ER+ cells to divide. This effect could be explained by the loss of a tumour suppresser gene, the normal function of which is to prevent excessive proliferation of $\mathrm{ER}+$ cells in environments rich in oestrogens. Allelic imbalance has been demonstrated at many chromosomal loci in intraductal and intralobular proliferations of the breast and is significantly more common within in situ carcinomas and atypical hyperplasias than hyperplasia of usual type. ${ }^{19-21}$ The location of such a gene is at present a matter of pure con- jecture. To date, allelic imbalance has not been investigated adequately in the benign lesions studied here because of the substantial difficulties in isolating pure enough populations of epithelial cells from histological sections. However, laser microdissection might overcome this problem.

The low risk lesions investigated in our study have many features in common with HUT. They contain significantly greater percentages of ER+ and ER+/Ki67+ cells and exhibit higher $\mathrm{O} / \mathrm{E}$ ratios for dual expression than normal premenopausal lobules, but less than low nuclear grade DCIS. ${ }^{9}$ This suggests that the molecular abnormality responsible for ER and Ki67 dissociation within neoplastic breast tissue is incompletely developed within low risk lesions. The presence of similar molecular abnormalities in the low risk lesions and HUT argues that they are precursor lesions, and suggests that the abnormal regulation of ER might be an important part of the precancerous process. These lesions are, however, only associated with a low relative risk of between 1.7 and 2.1,5 ${ }^{710^{14-16}}$ and most women in whom these lesions are diagnosed will not subsequently develop invasive breast cancer. The pronounced variability in abnormal ER expression needs further investigation to determine whether women whose lesions show greatest abnormality are those who are more likely to develop invasive breast cancer.

The finding that the male breast contains large numbers of ER+ cells regardless of age supports the view that oestrogen concentrations normally have a major effect on ER+ cell numbers. High hormone concentrations, as seen in premenopausal and lactating women, are associated with low numbers of ER+ cells, whereas low concentrations of oestrogen, as seen in postmenopausal women and men, are associated with high numbers of ER+ cells. However, the presence of $\mathrm{ER}+/ \mathrm{Ki} 67+$ in the male breast is more difficult to explain because there is no good evidence that gynaecomastia is precancerous. However, it is not known whether the breast epithelial cells in this condition lack the genetic instability of proliferative lesions in women, or whether the molecular changes in the female breast lead to malignancy only in the appropriate hormonal milieu. Certainly, the sex hormonal differences between men and women mean that it is not possible to extrapolate the function of ER from one gender to the other, or its role in breast carcinogenesis.

We are especially grateful to the Cancer and Polio Research Fund, which provided a grant to BSS, and for the support and facilities provided by Clatterbridge Cancer Research Trust. 1 Howell A. Clinical evidence for the involvement of oestrogen
in the development and progression of breast cancer.
Proceeding of the Royal Society of Edinburgh 1989;95B:49-
57 .
2 Kelsey JL, Gammon MD, John EM. Reproductive and hor-
monal risk factors: reproductive factors and breast cancer.
Epidemiol Rev 1993;15:36-47.
3 Clarke RB, Howell A, Potten CS, et al. Dissociation between
steroid receptor expression and cell proliferation in the
human breast. Cancer Res 1997;57:4987-91.
4 Dupont WD, Page DL. Risk factors for breast cancer in
women with proliferative breast disease. $N$ Engl $f$ Med
$1985 ; 312: 146-51$. 
5 Carter CL, Corle DK, Micozzi MS, et al. A prospective study of the development of breast cancer in 16,692 women with benign breast disease. Am $\mathcal{f}$ Epidemio 7-77

6 London SJ, Connolly JL, Schnitt SJ, et al. A prospective study of benign breast disease and the risk of breast cancer. FAMA 1992;267:941-4.

7 Bodian CA, Perzin KH, Lattes R, et al. Prognostic significance of benign proliferative breast disease. Cancer 1993;71:3896-907.

8 Shoker BS, Jarvis C, Sibson DR, et al. Oestrogen receptor expression in the normal and pre-cancerous breast. $\mathcal{F}$ Pathol 1999;188:237-44.

9 Shoker BS, Jarvis C, Clarke RB, et al. Oestrogen receptor-positive proliferating cells in the normal and precancerous breast. Am f Pathol 1999;155:1811-15.

10 Jensen RA, Page DL, Dupont WD, et al. Invasive breast cancer risk in women with sclerosing adenosis. Cancer

11 Page DL, Salhany KE, Jensen RA, et al. Subsequent breast carcinoma after biopsy with atypia in a breast papilloma. Cancer 1996;78:258-66.

12 Sloane JP, Mayers MM. Carcinoma and atypical hyperplasia in radial scars and complex sclerosing lesions-importance of lesion size and patient age. Histopathology 1993;23:22531.

13 Douglas-Jones AG, Pace DP. Pathology of R4 spiculated lesions in the breast screening programme. Histopathology 1997;30:214-20
14 Jacobs TW, Byrne C, Colditz G, et al. Radial scars in benign breast-biopsy specimens and the risk of breast cancer. $N$ Engl f Med 1999;340:430-6.

15 Dupont WD, Page DL, Parl FF, et al. Long-term risk of breast cancer in women with fibroadenoma. $\mathrm{N} \mathrm{Engl} \mathrm{f} \mathrm{Med}$ 1994;331:10-15.

16 McDivitt RW, Stevens JA, Lee NC, et al. Histologic types of benign breast disease and the risk for breast cancer. Cancer 1992;69:1408-14

17 National co-ordinating group for breast screening pathology. Pathology reporting in breast cancer screening, 2 nd ed. NHSBSP publication no. 3, Sheffield: NHSBSP Publications, 1997:1-65.

18 Zelada-Hedman $M$, Werer $G$, Collins $P$, et al. High expression of the EGFR in fibroadenomas compared to breast carcinomas. Anticancer Res 1994;14:1679-88.

19 Stratton MR, Collins N, Lakhani SR, et al. Loss of heterozygosity in ductal carcinoma in situ of the breast. $f$ Pathol 1995;175:195-201.

20 Lakhani SR, Collins N, Stratton MR, et al. Aypical ductal hyperplasia of the breast: clonal proliferation with loss of heterozygosity on chromosomes $16 \mathrm{q}$ and $17 \mathrm{p} .7$ Clin Pathol 1995;48:611-15.

21 Lakhani SR, Slack DN, Hamoudi RA, et al. Detection of allelic imbalance indicates that a proportion of mammary hyperplasia of usual type are clonal, neoplastic proliferations. Lab Invest 1996;74:129-35.

\section{PATHOLOGY INTERACTIVE 2000}

\section{Do you know ....?}

Pathology Interactive Volume 2 now offers:

Up to three CPD credits per review article

1 credit for reading the article and completing the associated questions

1 credit for additional reading, following up references

1 credit for making notes, identifying learning outcome or identifying further learning needs

CPD credits for working on articles outside your specialty

\section{Pathology Interactive Volume 2 Issue 1 includes articles in:}

Microbiology

Histopathology

Molecular pathology

\section{Further issues in $\mathbf{2 0 0 0}$ will cover further articles in these specialties, plus:}

Chemical pathology

Haematology

Immunology

Including case study and picture quiz formats

Pathology Interactive 2000 Volume 2, 4 issues (March, June, September, December) ISSN 14665743 Accredited by the Royal College of Pathologists

Subscription rate: $£ 75+$ VAT personal ${ }^{\star}, £ 150$ +VAT institutional (multiuser rate on application to the publisher).

Send orders to: BMJ Publishing Group, Journals Marketing Dept. PO Box 299, London WC1H 9TD, UK; fax credit card orders to: +44 (0)20 7383 6402; call subscriptions hotline +44(0)207383 6270; email orders to: subscriptions@bmjgroup.com

*ACP members receive Pathology Interactive with their copy of fournal of Clinical Pathology, as a membership benefit. 